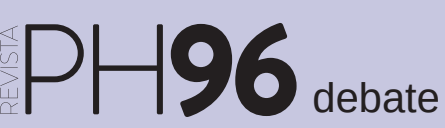

a debate Memoria democrática en la construcción de la historia y el patrimonio

| coordina Josefina Cuesta Bustillo

\title{
La memoria democrática en el juego entre memoria y cultura
}

María del Rosario Zavala | Facultad de Ciencias Políticas y Sociales, Universidad Nacional de Cuyo (Argentina)

URL de la contribución <www.iaph.es/revistaph/index.php/revistaph/article/view/4296>

Podemos pensarnos de muchas maneras. Sin embargo, nada se entiende si no partimos del análisis de nuestra propia situación. $Y$ desentrañarla supone insertarnos plenamente en nuestra cultura. La propuesta es escribir las situaciones de ese mundo, las constitutivas de la memoria de la cultura como proyecto.

Desde el punto de vista de una relocalización de nuestro campo de significaciones, dentro de las problemáticas propias de las comunidades específicas, en el marco de los debates sobre cultura y memoria, es difícil seguir hablando de la cultura como una categoría homogénea y totalizadora, por lo que partimos desde una idea de cultura procesual y cambiante. Es posible comprender a la cultura desde perspectivas abiertas a plantear otros modos de articulación entre las prácticas, los hechos y el mundo social. Bajo una idea que trata de comprender que el acceso a bienes y servicios culturales garantiza el desarrollo de la creatividad, la fantasía, la comprensión y la reflexión y que pueden transformarse en herramientas para la elaboración de un juicio crítico sobre la realidad social inmediata, así como medios para imaginar nuevos mundos posibles y nuevas formas de ser en el mundo.

La cultura se produce, circula y consume a través de los procesos sociales e históricos y de allí su complejidad, por la que se conjuga como una trama simbólica dada en la lógica de interacción de partes distintas, idénticas y similares, configurándose como un campo de posibilidades en el que se incluye de manera contingente el conflicto social. Por más pequeñas que sean, siempre hay espacios, prácticas e instituciones para nuestras representaciones.

Por su parte, la memoria se obtiene y construye de distintas maneras, con distintos materiales y mecanismos, conjugándose con los recuerdos del pasado de un grupo social, de una comunidad, de una sociedad, lo que contribuye al fortalecimiento de su identidad y así forma parte de los procesos culturales. De modo tal que las prácticas y procesos, principalmente culturales, deciden qué se recuerda y qué se mantiene en la memoria, repercutiendo en la identidad que a su vez decide sobre el sentido de esas prácticas y esos procesos. Entonces, la cultura entendida como una instancia comunicacional entre lo práctico productivo y lo significante se constituye por el despliegue del carácter en donde la identidad de los sujetos como tales debería evidenciarse.

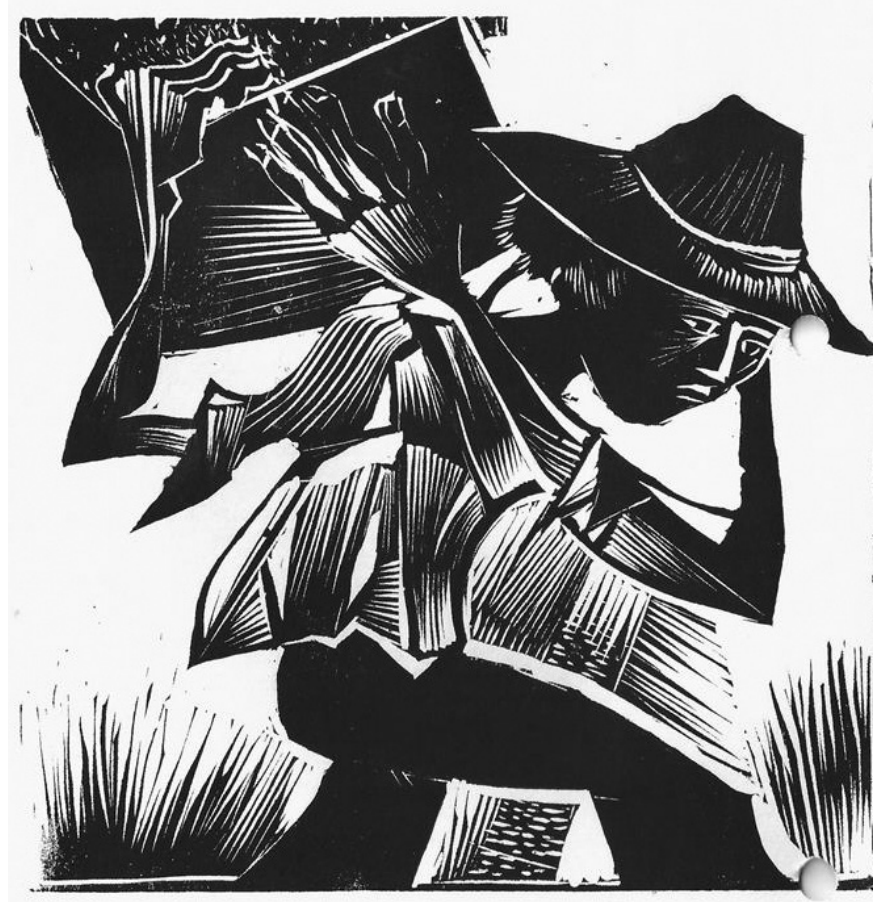

Las prácticas del arte, en postdictadura, se asocian al trabajo de una memoria particular que relaciona cultura y democracia. Detalle de folleto de una muestra por los derechos humanos en 1984 del Museo Municipal de Arte Moderno de Mendoza | fuente Archivo MMAMM, Mendoza 
Nos conocemos entre colonización y dominación, pero al mismo tiempo, contamos con la posibilidad de una comunicación destinada a romper las formas de exclusión, nuevas redes y conexiones, nuevas experiencias de interacción con una trama simbólica común. El riesgo del olvido y la impunidad hacen de éste un tema de la agenda cultural y política actual. Por lo que, en nuestra contemporaneidad, internarnos en los procesos culturales no solo trata de evidenciar la imposición de identidades, sino, sobre todo, de resaltar y rescatar esta dimensión como un largo y profundo proceso de revolución cultural, donde las formas culturales, en un contexto complejo, se transmiten como mensajes, como sistemas simbólicos.

A medida que la corriente cultural actual se va formando, surgen nuevos escenarios de producción, de su valor y de su sentido. Espacios emergentes que obligan a redefinir las posiciones de todos los productores, la delimitación del campo, la definición de los roles y la legitimidad de la cultura. El debate sobre el lugar de la cultura, como dimensión en proceso de configuración, y su vinculación con lo político, abarca espacios muy amplios. La construcción de los nuevos mundos simbólicos en la era de las trasnacionales, la desindustrialización y el avance de nuevas formas de acción indican la emergencia de una multiplicidad de prácticas culturales como parte de una nueva razón populista y de un nuevo proceso histórico.

Algo está irrumpiendo en la escena contemporánea y requiere ser abordado por nuestros análisis: la pluralidad, la diferencia y el antiautoritarismo. Esto implica una revisión de los acontecimientos de nuestra historia reciente, que necesitan ser tomados en cuenta para romper con los estigmas de una propuesta trunca y repensar las continuidades y las rupturas, al menos para no enclavarnos en la nostalgia y comenzar a quitar lo nefasto. Pues el valor sobre el tiempo pasado, presente y futuro se monta sobre diferentes configuraciones, en cada espacio simbólico presente. Es entonces una posibilidad hablar de la memoria democrática desde la cultura, como parte de una configuración cultural, en oposición al olvido, a la reconciliación y a la amnistía.
En este marco, el golpe dado por la dictadura militar argentina fue parcialmente saldado en la transición democrática y, luego de 30 años, encontraron una corta instancia de respuestas desde las políticas del estado (2003-2015). Pasado, presente y futuro se encadenan en una trama que alienta la revisión del sentido atribuido a determinados fenómenos. Y, demarcado por los pasados dictatoriales y los presentes portadores de las huellas de la represión estatal, el tema de la memoria se constituye como público.

\section{BIBLIOGRAFÍA}

- GRIMSON, A. (2011) Los límites de la cultura. Buenos Aires: Siglo XXI, 2011

- ECHEVERRÍA, B. (2001) Definición de la cultura. México: Ítaca, 2001

- JELIN, E. (2002) Los trabajos de la memoria. España: Siglo XXI, 2002

- RICHARD, N. (2007) Fracturas de la memoria; Arte y pensamiento crítico. Buenos Aires: Siglo XXI, 2007

- VINYES R. (2009) El estado y la memoria. Gobiernos y ciudadanos frente a los traumas de la historia. España: RBA, 2009 